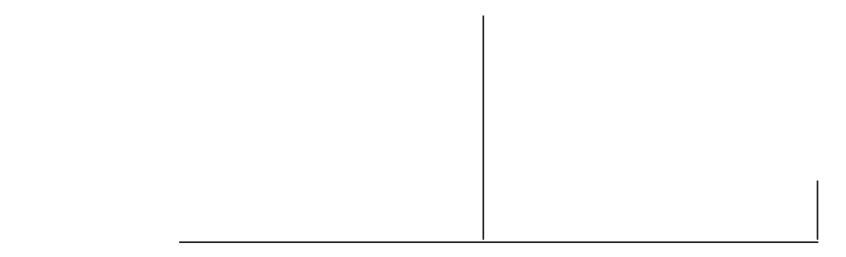

Rev. Latinoam. Psicopat. Fund., V, 3, 69-82

\title{
Melancolia e depressão com especial atenção para a obra São Bernardo, de Graciliano Ramos*
}

\author{
Francisco Martins
}

\begin{abstract}
O trabalho estuda a dimensão da metáfora na melancolia. Busca-se diferenciar esta da depressão. É mostrado que as depressões se apresentam costumeiramente com metáforas de queda e de luta. Nas melancolias se acrescenta a dimensão do devenir como sendo alterada na profundidade do corpo próprio. Dois aspectos ligados ao corpo são valorizados e transparecem a dificuldade de devenir do ponto de vista das metáforas apresentadas pelos melancólicos: a desvitalização e o entravamento radical do ir e vir. Os verbos subir e descer e principalmente ir e vir são apontados como importantes nas metáforas, justamente por expressarem o bloqueio do sentir fundamental e portanto do devenir. Exemplos do romance São Bernardo de Graciliano Ramos são apresentados e discutidos.
\end{abstract}

Palavras-chave: Melancolia, depressão, metáforas, Graciliano Ramos

\footnotetext{
* Este trabalho contou com apoio do CNPq, sem o qual não seria possível a sua realização e apresentação.
} 


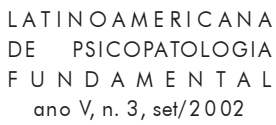

\section{Introdução}

Humor negro. Sol eclipsado. Terror da falta do centro de energia do universo. Secreção negra que cola e obstrui vísceras. Obstrução de atividade visceral. Desde suas origens a melancolia (Corpus Hipocraticus) é reconhecida como a bílis negra, acompanhada dos seus sentidos frontais e dos colaterais. Estes sentidos variam. Ocorre que, em bom número de tratados psicopatológicos, ela seja reconhecida pela presença de uma tristeza irremediável, acompanhada de intensa dor moral. Essa tristeza é acompanhada de modificações nas sensações, no sentir fundamental principalmente através de sensações cenestésicas de parada de movimento. É uma tristeza vital onde o caráter de falta de fluência no tempo e no espaço tem sua marca característica. Em todas as descrições clássicas encontramos a presença da inibição da atividade geral do organismo. Esta inibição se vê relacionada a alterações dos diversos ritmos biológicos essenciais como sono vigília, a oscilação diária da temperatura, a oscilação hormonal, o ritmo circadiano, o ciclo atividade-repouso, o ritmo apetite-saciedade.

Já o termo depressão tem origem mais recente e se relaciona com o rebaixamento da atividade, com a experiência de situar-se nas partes mais baixas de um território. Isto é, em qualquer recorte de um signo clínico em um momento da história há, na visão do observador, o privilégio de metáforas essenciais. Como vemos, na observação clássica relacionada aos termos designadores melancolia e depressão, estão presentes imagens que atravessam o olhar do observador. Ou seja, encontramos, no fundamento do lexema, dimensões colaterais que estão plenas de linguagem ordinária e comprometidas com metáforas que circulam previamente na linguagem comum. 


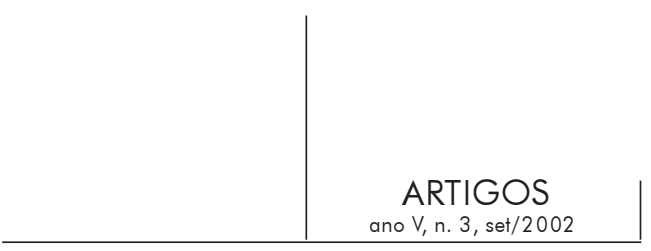

Os critérios de diagnose das depressões, nas classificações mais reconhecidas, tomaram o caminho de utilização de signos que tendem a excluir dados vindos da linguagem ordinária, passando a qualificar a busca de signos observáveis diretamente. Esta vocação, por exemplo, tem sido salientada por meio da utilização dos critérios de definições operacionais vindas da epistemologia de Hempel (1994, p. 315-31). A criação destes critérios é um avanço normalizador, porém não resolve o fato essencial que estes signos são colhidos principalmente via a linguagem ordinária e vêm acompanhados de outros signos. A reivindicação de cientificidade parece passar pela exclusão de fatos que fazem parte da clínica dos distúrbios timopáticos desde sempre, sob pena de excluir grande parte da dor e apreciação dos próprios pacientes.

\section{O campo das timopatias}

A tendência fenomenológica advinda de Tellenbach (1976) sublinha as alterações do ritmo do acontecer vital, em especial a cinesis, como sendo essencial para o desenvolver-se da sintomatologia depressiva clássica. É importante salientar, porém, que as tentativas de separar um quadro estritamente endógeno em oposição ao reativo se mostrou infrutífero, posto que nos ditos quadros reativos podem ser encontrado muitos dos signos típicos da endogeneidade. A psicopatologia transcultural contribuiu sobremaneira para percebermos que o essencial fundador está ligado a primeiridade descrita por Peirce, ao acontecer primeiro, ao frescor original. Isto é, descobriu-se a inexistência de quadros de melancolia típica do ocidente, qual seja a dor moral, a tristeza, as idéias suicidas, a autodesvalorização, em grupos que não foram ainda aculturados. No entanto, as experiências de desvitalização, de perda de movimento, de esgotamento, de intensa abulia se fazem presentes. ${ }^{1}$

A partir do que aprendemos com Jacques Schotte (1982, p. 621-73), entendemos as timopatias (ou grosso modo, os distúrbios do humor) como sendo um campo específico do ponto de vista pathoanalítico. Essencialmente, este campo é dominado por uma semiologia clínica regida de um ponto de vista lógico

1. Por exemplo, os estudos de H. Collomb e J. Zwingelstein, "Depressive states in an Afrikan community (Dakar)" First Pan-African Conference, Abeokuta [Nigeria], 1962, p. 227-34 e estudado também por Edmond Ortigues e Marie-Cecile Ortigues, em Édipo Africano. 


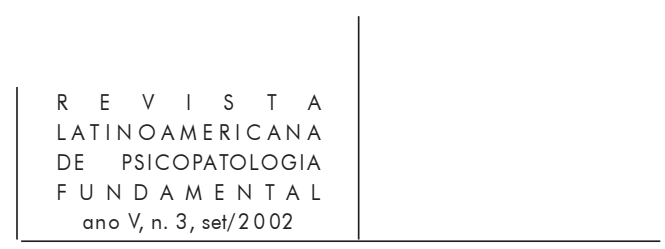

por signos da primeiridade conforme a semiologia de C.S. Peirce, ou seja, onde a problemática psicológica do sentir é fundamental e radical. Tanto nas depressões quanto nas melancolias e nas distimias, esta dimensão é atingida fundamentalmente. Ocorre, porém, que não existe isolamento no processo semiológico. Não é difícil, ao longo da vida, principalmente na velhice, vermos uma neurose grave tender para a cristalização de uma depressão inicial e progredir para a imagem psiquiátrica da melancolia de involução no seu destino mais tenebroso.

A título de lembrança, indicamos no quadro a seguir os critérios gerais que geraram a classificação dos signos segundo Peirce e a correlação que propomos para leitura das questões timopáticas na tabela II. A metáfora é elemento natural da primeiridade daí estar presente em todas as situações onde se envolvam imagens e linguagem.

Tabela I

Caracterização geral das semiológicas de Peirce

\begin{tabular}{|c|c|c|c|c|}
\hline 72 & $\begin{array}{l}\text { Categorias } \\
\text { Peircianas } \\
\end{array}$ & $\begin{array}{c}1 \\
\text { Firstness } \\
\end{array}$ & $\begin{array}{c}2 \\
\text { Secondness }\end{array}$ & $\begin{array}{c}3 \\
\text { Thirdness } \\
\end{array}$ \\
\hline & Temporalização & Presente & Passado & Futuro \\
\hline & $\begin{array}{l}\text { Caracterização } \\
\text { semiológica }\end{array}$ & Sensação & Experiência & $\begin{array}{c}\text { Consciência } \\
\text { do futuro }\end{array}$ \\
\hline & $\begin{array}{l}\text { Tipos de } \\
\text { consciência }\end{array}$ & $\begin{array}{l}\text { Impressão } \\
\text { (Feeling) }\end{array}$ & $\begin{array}{l}\text { Reação } \\
\text { (Reaction) }\end{array}$ & $\begin{array}{c}\text { Pensamento } \\
\text { (Thought) }\end{array}$ \\
\hline & $\begin{array}{l}\text { Setores } \\
\text { filosóficos }\end{array}$ & Estética & Ética & Lógica \\
\hline & $\begin{array}{l}\text { Princípio de } \\
\text { semiosis }\end{array}$ & Talidade & Causalidade & Lei \\
\hline & $\begin{array}{l}\text { Caracterização } \\
\text { de semiosis }\end{array}$ & Qualidade & Conflito & Mediação \\
\hline & $\begin{array}{l}\text { Caracterização } \\
\text { do fenômeno }\end{array}$ & O sensível & O evento & A razão \\
\hline & $\begin{array}{l}\text { Caracterização } \\
\text { psicológica }\end{array}$ & Sentir & Querer & Pensar \\
\hline
\end{tabular}




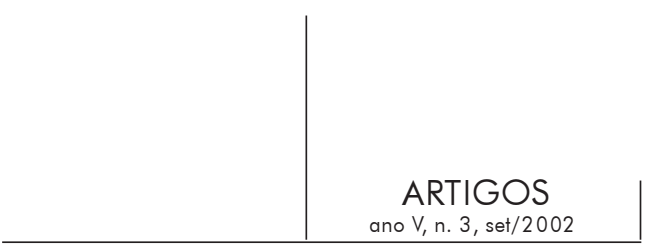

Caso retomemos a caracterização geral, poderemos propor uma leitura das síndromes psíquicas da seguinte maneira.

Tabela II

Caracterização geral semiológica das síndromes psíquicas

\begin{tabular}{|c|c|c|}
\hline $\begin{array}{c}\text { Síndromes Psicoafetivas } \\
\text { (timopáticas) }\end{array}$ & $\begin{array}{c}\text { Síndromes Perverso } \\
\text { neuróticas }\end{array}$ & Síndromes Psicóticas \\
\hline 1 & 2 & 3 \\
\hline Sensorialidade & Reatividade & Procescesso a \\
\hline Ciclo & Paroxismo e Estado & Terceiridade \\
\hline Primeiridade & Segundidade & \\
\hline
\end{tabular}

Conforme fica evidente, os critérios de primeiridade problematizada nos parecem ser bastante próximos daquilo que encontramos na psicopatologia das melancolias: a dificuldade no sentir fundamental. Dizemos aqui sentir no sentido daquilo que em inglês é designado como sendo feeling e não feeling of. Ou seja, aquilo que é visto como se passando no durativo e não no particípio passado, aquilo que se passa na enunciação e não somente no enunciado, aquilo que se passa em ato e não somente aquilo já tornado um objeto. As melancolias nos parecem atingir justamente esta dimensão do sentir primeiro. Já as depressões nos parecem tocar a dimensão do feeling of, da reatividade face a algo experimentado.

\section{A metáfora nas melancolias e nas depressões}

Examinemos primeiro as metáforas nas depressões. "The love you make is the love you get" é um dístico de pessoas que viveram " 68 " e de grande número de depressões atualmente vigentes no mundo. Fico feliz de ver que é um ditado ainda válido, especialmente para os amores de todos os dias, aqueles que encontramos e buscamos construir em nossas vidas. Questões do tipo "Até onde você me ama?", "O quanto você, meu antigo amor, me odeia agora?" só levam às depressões do cotidiano, principalmente aquelas das neuroses. Neste caso, 


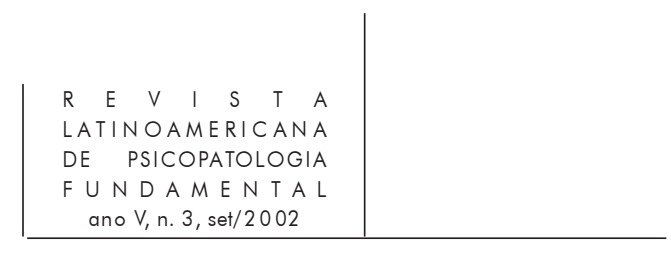

usando uma terminologia antiga fenomenológica, dizemos existir comércio, troca e, de um ponto de vista estruturalista, existir algo que fundamenta a existência das relações nas mais diversas sociedades, qual seja a exigência de reciprocidade (Mauss, 1950). O verbo amar pode ser intransitivo, mas para a maioria das pessoas não-melancólicas, ele se inscreve como uma atividade que necessita de objetos. Assim, quando alguém testa o outro acerca da capacidade de amar, se inscreve dentro de uma estrutura. Segue a lógica de algo que já existe, e que somos gratos e devedores nas relações de reciprocidade e de solidariedade que constitui nossa humanidade comum. Ou seja, para você discutir se alguém pode lhe amar ou não, ele tem que existir.

Aqui merece ser feita uma distinção essencial entre a capacidade e modo de amar nas melancolias e nas depressões. Justamente nas melancolias se chega a ponto de pensar não existir este objeto primário de amor suporte (se podemos chamar de objeto). Cessa o teste de ser amado tal como descrevemos há pouco com relação às depressões. O campo de batalha é, agora, entre o Eu e o suporte do mesmo, o corpo. Neste aspecto, fica saliente o devenir do Ser como estando alterado.

Quando dizemos devenir, pensamos no "ir - vir" em acontecimento tal como experimentamos o transcurso em ato da nossa existência. O devenir perturbado é acessado nas mais diversas línguas por intermédio de expressões acerca do ir e vir, do caminhar na estrada da vida. Como vai? é uma expressão comum que inicia o contacto e explora o devenir do sujeito. Ir implica mobilidade além da intencionalidade do Eu. Este último experimenta o devenir, o transformar-se, o repetir-se de forma bloqueada, acelerada ou simplesmente como um devenir desregulado, desequilibrado. Vir implica estas dimensões do devir, exprimindo o regresso e origem, de volta ao que é familiar e menos estranho. Tanto no ir como no vir, o sentir, acompanhado da experiência de vitalidade, torna-se essencial. Daí as imagens relacionadas ao corpo vivido, bem como as sensações de plenitude e esvaziamento de energia, serem essenciais no reconhecimento das alterações do humor. Ou seja, as metáforas e expressões da linguagem cotidiana, por mais enganos que promovam, continuam sendo signos essenciais no reconhecimento das timopatias.

Se a melancolia nos serviu de tema para introduzir o problema do devenir e da semiologia do ir e vir, e por consequiência de metáforas relacionadas com estes verbos, entendemos que os distúrbios mais comuns são aqueles relacionados com o que chamamos toxicomanias. Evidentemente que o termo não visa o entendimento a partir do objeto "droga", o tóxico, mas principalmente na direção do termo mania no sentido popular. Existem as desregulações cotidianas dos ritmos onde o sujeito se sente ir. Daí pensar sempre em se harmonizar. Logo que alguém localiza a possibilidade desta harmonia em um objeto concreto a ser 


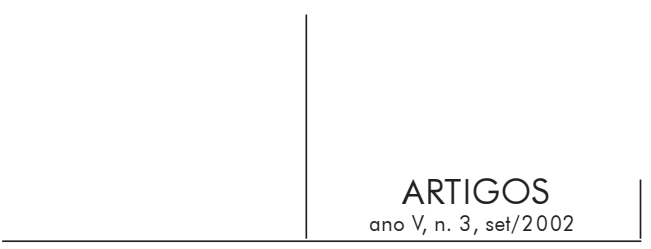

colocado dentro do corpo, vemos o substrato do devenir alterado. As drogadições mais radicais e resistentes encontram seu substrato nesta problemática primeira do devenir, existindo, é claro, drogadições do ponto de vista do sujeito, de ordem das neuroses e psicoses.

Já o maníaco típico experimenta algo diferente da melancolia e da toxicomania. Binswanger elucidou que o maníaco é alguém que sobe mas que se perde nesta subida. Contudo, antes de subir ou descer, tal como foi caracterizado pelos termos polarizados depressão - mania, nas psicoses que chamamos de base psicopática ocorre uma perturbação no devenir. As experiências de uma energia desmesurada fazem aparecer signos de um ir e vir um tanto quanto disperso e sem direção. Os ritmos são acelerados, situando-nos não no clima de desespero, das lamentações e de velório, tal como na melancolia, mas na atmosfera do footing das cidades do interior ou das quermesses das festas juninas.

Todos estes distúrbios (distimias, toxicomanias, quadros maníacos) nos levam a pensar o grupo das doenças psíquicas do humor como sendo derivado da dificuldade de participar do ritmo, da atmosfera (Stimmung; mood), do ir e vir "global ambiente da natureza e da vida neste conjunto primordial de seus sentidos que encontra igualmente sua verdade na obra de arte" (Sehotte, 1982). Aqui pensamos essencialmente nas melancolias como sendo um bloqueio do ir e vir fundamental. Diferentemente, as depressões implicam objetos de desejo de conflito e de falta. Implicam a aspiração idealizada de vir a ser. Daí falar-se em uma semiologia do subir e descer que se encontra implicada nos quadros graves de distúrbios do humor, articulados com algo já do pensar. As metáforas de queda se tornam então pregnantes nas depressões graves e nas melancolias. Nas depressões, o devenir não estaria tão bloqueado. A sensação de queda não é referida diretamente e sempre nas metáforas dos deprimidos. Elas aparecem quase sempre logo que existe uma exigência ligada ao dever. Ou seja, quando o sujeito, tal como ocorre com o personagem de Dostoiévski, em Crime e Castigo, Raskólnikov, se implica com uma idéia vinda do alto, do dever. A obrigação então de realização idealista, onde as metáforas de verticalização do corpo próprio são denunciadoras do orgulho e da concepção do ser humano como ser de "cabeça em pé, erguida".

Podemos ilustrar o exposto a pouco por intermédio de um relato, proveniente da história de um homem que depois de ser um vencedor, após a morte da esposa, passa então por uma grave perturbação timopática. Trata-se de Paulo Honório, personagem principal do romance de Graciliano Ramos (1953), que entendemos como uma estrutura neurótica obsessiva, mas que apresenta, no final de sua vida, um quadro bastante contaminado por signos de uma melancolia grave em instalação continuada. Citaremos algumas passagens que são significativas do 


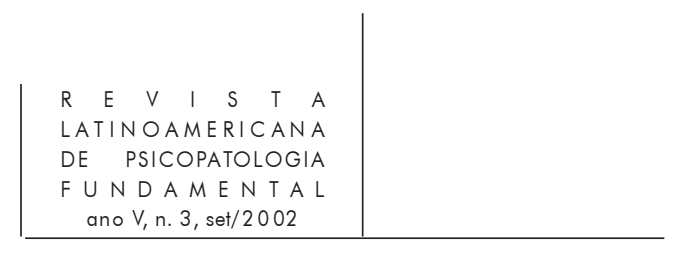

estado em que se encontra Paulo Honório, ou seja, um estado infiltrado de signos depressivos, instalando-o, no final da história, na parte baixa da ciclicidade, a melancolia.

Paulo Honório inicialmente é um homem essencialmente conflitado, acometido de remorsos, luta interna e, por conseqüência, de depressão. Além disto, é concernido com o dever e o aparentar problematizado. O subir e o descer são percebidos e adquirem conotação com relação ao dever. Estamos diante, portanto, de alguém profundamente narcísico, que não tem muita consideração pelos outros. O subir e o descer é uma medida acerca do ideal que o sujeito alcançou e fez enquanto dever. Implica em um pensar qualificado que é tomado como exigência máxima. Afigura-se então o problema basal do pensar, que introduz uma clínica tão profundamente narcísica como a descrita. Localizamos Paulo Honório, no seu final de vida, como um sujeito melancólico. Com efeito, no capítulo final do romance, existe o aparecimento do problema do devenir como sendo o mais radical e o concomitante aparecimento de perturbações no ir e vir do sujeito. Quando ele diz ser um sujeito arrasado agora a metáfora é muito mais que uma simples analogia. Ela exprime um désarroi sem fundo, ela configura um mundo com sentidos existenciais onde o corpo próprio se vê acometido. Ocorre um transporte também de tonalidade fundamental.

Examinemos as diversas passagens de forma mais didática:

\begin{tabular}{|c|c|c|c|}
\hline Original português & $\begin{array}{l}\text { Tradução } \\
\text { inglês }\end{array}$ & $\begin{array}{l}\text { Tradução } \\
\text { francês }\end{array}$ & Análise semiológica \\
\hline $\begin{array}{l}1 \text { "Sou um homem arrasado. } \\
\text { Doença? Não. Gozo perfeita } \\
\text { saúde. (...) Não tenho doença } \\
\text { nenhuma. }\end{array}$ & & & $\begin{array}{l}\text { No excerto } 1 \text { o termo arrasado, } \\
\text { envia-nos a imagem do } \\
\text { rebaixamento e de estar na parte } \\
\text { baixa, rasa, mostrando Paulo } \\
\text { Honório não ser mais um homem } \\
\text { verticalizado. Ele está vencido e } \\
\text { horizontalizado, não podendo se } \\
\text { erguer a não ser com um grande } \\
\text { esforço. Está caído em uma terra } \\
\text { destruída, onde é impossível } \\
\text { frutificar. Estamos situados no } \\
\text { problema típico das depressões } \\
\text { com as metáforas de queda. Mas } \\
\text { chamamos atenção que alguém } \\
\text { horizontalizado não vai nem vem. } \\
\text { Ou seja, do ponto de vista } \\
\text { daquele que sofre é mais gritante } \\
\text { o sofrimento por não poder ir } \\
\text { subir, se soerguer do que mesmo } \\
\text { o fato que está caído. }\end{array}$ \\
\hline
\end{tabular}


ARTIGOS

ano $V, n .3$, set/2002

\begin{tabular}{|c|c|}
\hline $\begin{array}{l}2 \text { O que estou é velho. } \\
\text { Cinqüenta anos pelo S. Pedro. } \\
\text { Cinqüenta anos perdidos, } \\
\text { cinqüenta anos gastos sem } \\
\text { objetivo, a maltratar-me e a } \\
\text { maltratar os outros. O resultado } \\
\text { é que endureci, calejei, e não } \\
\text { é um arranhão que penetra } \\
\text { esta casca espessa e vem ferir } \\
\text { cá dentro a sensibilidade } \\
\text { embotada. }\end{array}$ & $\begin{array}{l}\text { No excerto } 2 \text { o tempo e a velhice } \\
\text { não são vistos como algo subli- } \\
\text { me. São fonte de criação de so- } \\
\text { frimento, justificativa e expressão } \\
\text { conflitiva de Paulo Honório. Ocor- } \\
\text { re então o aparecimento de uma } \\
\text { agressividade contra si mesmo e } \\
\text { sem saída. Uma violência irreme- } \\
\text { diável. Chamaríamos de bom gra- } \\
\text { do de auto fustigamento, todas } \\
\text { estas expressões que situam o } \\
\text { sujeito na secundidade. }\end{array}$ \\
\hline $\begin{array}{l}3 \text { Cinqüenta anos! Quantas ho- } \\
\text { ras inúteis! Consumir-se uma } \\
\text { pessoa a vida inteira sem sa- } \\
\text { ber para quê! Comer e dormir } \\
\text { como um porco! Como um por- } \\
\text { co! Levantar-se cedo todas as } \\
\text { manhãs e sair correndo, procu- } \\
\text { rando comida! E depois guar- } \\
\text { dar comida para os filhos, para } \\
\text { os netos, para muitas gera- } \\
\text { ções. Que estupidez! Que por- } \\
\text { caria! Não é bom vir o diabo e } \\
\text { levar tudo? (...) }\end{array}$ & $\begin{array}{l}\text { No excerto } 3 \text { o autofustigamento } \\
\text { prossegue por intermédio de uma } \\
\text { intensa desvalorização do que foi } \\
\text { construído com tanto esforço ao } \\
\text { longo da vida. Vemos uma das } \\
\text { sublimações mais importantes do } \\
\text { personagem serem desconstruí- } \\
\text { das por intermédio do esvazia- } \\
\text { mento do conteúdo significativo } \\
\text { das obras. Trata-se de lutar con- } \\
\text { tra aquilo que foi construído. Tra- } \\
\text { ta-se de desqualificar o trabalho } \\
\text { realizado. Vemos então o horizon- } \\
\text { te de objetos de desejo desapa- } \\
\text { recer. Paulo Honório deixa de ser } \\
\text { o homem agressivo, vencedor, vo- } \\
\text { raz, novo latifundiário, lobo do ho- } \\
\text { mem, para se perceber como um } \\
\text { porco piau que vive solto buscan- } \\
\text { do somente manter-se vivo. }\end{array}$ \\
\hline $\begin{array}{l}4 \text { Hoje não canto nem rio. Se } \\
\text { me vejo ao espelho, a dureza } \\
\text { da boca e a dureza dos olhos } \\
\text { me descontentam. (...) }\end{array}$ & $\begin{array}{l}\text { No excerto } 4 \text { emergem novamen- } \\
\text { te as experiências estéticas rela- } \\
\text { cionadas ao prazer sensorial } \\
\text { corporalizado que é impossível de } \\
\text { ser mais experimentado. Ou seja, } \\
\text { seu corpo não sente mais o ir e } \\
\text { vir da vida por conta de uma ex- } \\
\text { periência essencial das melanco- } \\
\text { lias radicais: a desvitalização do } \\
\text { corpo próprio. O adjetivo dureza } \\
\text { mostra um corpo que perde sua } \\
\text { elasticidade e plasticidade. }\end{array}$ \\
\hline
\end{tabular}




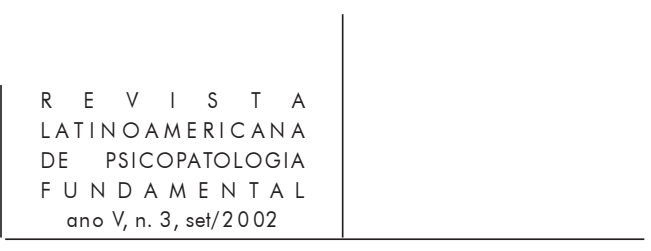

5 Levanto-me, procuro uma vela, que a luz vai apagar-se. Não tenho sono. Deitar-me, rolar no colchão até a madrugada, é uma tortura. (...)

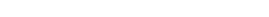

6 Ponho a vela no castiçal, risco um fósforo e acendo-a. Sinto um arrepio. A lembrança de Madalena persegue-me. Diligencio afastá-la e caminho em redor da mesa. Aperto as mãos de tal forma que me firo com as unhas, e quando caio em mim estou mordendo os beiços a ponto de tirar sangue.

De longe em longe sento-me fatigado e escrevo uma linha. Digo em voz baixa:

- Estraguei a minha vida, estraguei-a estupidamente.

A agitação diminui.

- Estraguei a minha vida estupidamente.

\begin{tabular}{|l|l|l} 
& \\
& &
\end{tabular}

No excerto $\mathbf{5}$ aparecem os signos de desregulação dos ciclos principiando pela insônia, mas também acompanhado por conflito ou tormento. Existe um indicativo de que sua insônia tem uma causalidade conflitual ou em outros termos de origem psíquica.

$\mathrm{Na}$ passagem 6 o atormentar-se toma forma e signo de forma cruel mais uma vez, posto que envolve o ferir o corpo próprio. Com efeito, Graciliano encontrou um modo de dizer o intenso remorso que acomete Paulo Honório. O remorso é mais forte que a culpa, talvez seja um grau mais elevado de intensidade e qualidade na agressividade contra si mesmo. Ou seja, o remorso como a própria origem da palavra denuncia implica um remorder-se. Morder de novo, até sair sangue, no mesmo local, de forma que já existe um veredicto e uma execução de inculpação no corpo próprio.

7 Penso em Madalena com insistência. Se fosse possível recomeçarmos... Para que enganar-me? Se fosse possível recomeçarmos, aconteceria exatamente o que aconteceu. Não consigo modificar-me. É o que mais me aflige. (...)

8 Madalena entrou aqui cheia de bons sentimentos e bons propósitos. Os sentimentos e propósitos esbarraram com a minha brutalidade e o meu egoísmo.

$\mathrm{Na}$ passagem seguinte (7), é saliente a impossibilidade de ir e vir, Paulo Honório está estagnado. Devenir é impossível, passando a ocorrer uma eterna repetição.

Nos excertos 8, 9 (assim como já tinha ocorrido no item 3) ocorre a inculpação de Paulo Honório. Vemos então o aparecimento de uma saída contra a inculpação: a profissão é a culpada. Ocorre assim um recurso inconsciente conhecido em psicanálise como projeção. Ao longo de sua vida Paulo Honório sempre pensava serem os outros os culpados. 


\section{ARTIGOS}

ano $V, n .3$, set/2002

\begin{tabular}{|c|c|}
\hline $\begin{array}{l}9 \text { Creio que nem sempre fui } \\
\text { egoísta e brutal. A profissão é } \\
\text { que me deu qualidades tão } \\
\text { ruins. } \\
\text { E a desconfiança terrível que } \\
\text { me aponta inimigos em toda a } \\
\text { parte! }\end{array}$ & $\begin{array}{l}\text { Projetando, acalmava os seus } \\
\text { conflitos com relação ao dever. } \\
\text { Mas, chegando ao final da vida, } \\
\text { face à tragédia e evidência do seu } \\
\text { casamento ruinoso, projetar não é } \\
\text { suficiente. Existe uma possibilida- } \\
\text { de tão ou mais grave que a pro- } \\
\text { jeção: a derivação para a depres- } \\
\text { são. }\end{array}$ \\
\hline $\begin{array}{l}10 \text { Foi este modo de vida que } \\
\text { me inutilizou. Sou um aleijado. } \\
\text { Devo ter um coração miúdo, la- } \\
\text { cunas no cérebro, nervos dife- } \\
\text { rentes dos nervos dos outros } \\
\text { homens. E um nariz enorme, } \\
\text { uma boca enorme, dedos enor- } \\
\text { mes. } \\
\text { Se Madalena me via assim, } \\
\text { com certeza, me achava } \\
\text { extraordinariamente feio. } \\
\text { Fecho os olhos, agito a cabe- } \\
\text { ça para repelir a visão que me } \\
\text { exibe estas deformidades } \\
\text { monstruosas. (...) }\end{array}$ & $\begin{array}{l}\text { No item } 10 \text { aparecem signos } \\
\text { relacionados ao corpo imaginado, } \\
\text { deformado e mutilado }\end{array}$ \\
\hline $\begin{array}{l}11 \text { Julgo que delirei e sonhei } \\
\text { com atoleiros, rios cheios e } \\
\text { uma figura de lobisomem. (...) }\end{array}$ & $\begin{array}{l}\text { No } 11 \text { imagens fortíssimas de } \\
\text { estranheza nos sonhos. As ima- } \\
\text { gens de "rios cheios, atoleiros" } \\
\text { mostram a obstrução que alguém } \\
\text { experimenta. Perturba-se intensa- } \\
\text { mente o ir e vir das pessoas. Ain- } \\
\text { da mais quando o livre ir e vir é } \\
\text { impedido por seres horríveis, fi- } \\
\text { guras da maldade e da não obe- } \\
\text { diência aos ditames do dever }\end{array}$ \\
\hline $\begin{array}{l}12 \text { É horrível! Se aparecesse } \\
\text { alguém... Estão todos dormindo. } \\
\text { Se ao menos a criança choras- } \\
\text { se... Nem sequer tenho amiza- } \\
\text { de a meu filho. Que miséria! } \\
\text { Casimiro Lopes está dormindo. } \\
\text { Marciano está dormindo. Pati- } \\
\text { fes! } \\
\text { E eu vou ficar aqui, às escuras, } \\
\text { até não sei que hora, até que, } \\
\text { morto de fadiga, encoste a ca- } \\
\text { beça à mesa e descanse uns } \\
\text { minutos". (p. 189-95). }\end{array}$ & $\begin{array}{l}\text { Finalmente na parte selecionada } \\
\text { 12, Paulo Honório fala da solidão } \\
\text { sentida. Signos de primeiridade } \\
\text { emergem, acompanhados em } \\
\text { seguida da produção de um } \\
\text { intenso ódio contra quem poderia } \\
\text { lhe fazer companhia. }\end{array}$ \\
\hline
\end{tabular}




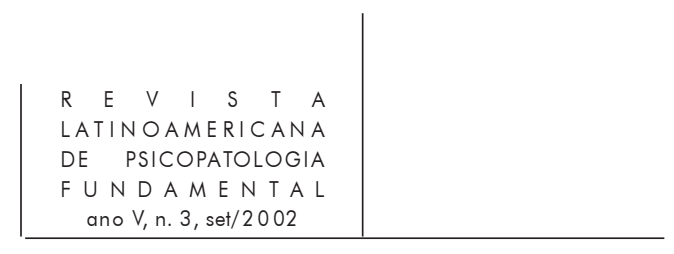

O problema de Paulo Honório, conforme vemos nos excertos analisados, pode ser caracterizado como sendo uma lenta e paulatina obstrução do devenir. Apontamos nos excertos diversos momentos onde o ir e o vir fundamental são afetados. É certo que ele continua com conflitos, mas suas queixas serão da ordem do contacto primário, onde o devir é essencial. Caso utilizemos termos comuns, que emergem na linguagem cotidiana derivada de conversas com pessoas que sofrem dos problemas que Paulo Honório experimenta, poderíamos concluir dizendo que nosso personagem é alguém entrevado no sentir fundamental e assim obstruído no seu devenir. Isto o coloca dentro da possibilidade de ter um destino tipo melancolia. Entrevar-se e obstrução do ir e vir são termos que permitem nos introduzir nos problemas do devir. Ocorre ruptura do comércio com os outros, consigo e com o mundo. Mas, mais que isso, nota-se um paulatino descompasso com o meio ambiente, com a atmosfera do vivente (Stimmung).

A passagem de uma problemática depressiva para uma problemática melancólica se faz por meio da paulatina e crescente insensibilidade. Esta é A descrição de Henry Maldiney (1997): “face à un melancolique psychotique, nous nous trouvons en présence d'une telle impermeabilité et pour ainsi dire, au sein même de sa douleur, d'une telle densité d'abscense que, selon l'erreur ordinaire, cette inacessibilité nous paraît provocante" (p. 90). Não temos dúvida de dizer que a melancolia, tal como ela se apresenta no final de Paulo Honório, é uma psicose, posto que o seu Eu encontra-se definitivamente naufragado na imobilidade e na insensibilidade. Ocorreu um ataque ao ground onde possa se desenrolar algo. Mas, mais além da auto-reprovação presente em depressões maiores e menores e que permeia toda e qualquer outra estruturação, vemos na melancolia o ataque ao Eu. Digamos que a auto-reprovação já foi ultrapassada e é tomada como passada e julgada: trata-se, agora, de simples aniquilamento.

A análise da frase típica de auto-reprovação melancólica: "Se eu não tivesse proposto, feito isto, aquilo não teria ocorrido", "Se eu não tivesse permitido aquilo, isso não teria ocorrido", "Se eu cuidasse melhor do meu marido, do meu filho, do meu amigo, eles não estariam tão mal". Como se vê, a auto-reprovação, como diz Binswanger, é cheia somente de possibilidade vazias ("se eu tivesse"), pois pertence ao passado que já está morto. No entanto este passado existe na protensão. Tanto na melancolia psicótica quanto nas depressões ela se encontra presente. Distinguimos então o progresso da depressão em direção a uma melancolia grave, o que implicaria a liquidação do conflito. O conflito tende a desaparecer, para crescer uma pura litania aniquilatória. Na melancolia, o aniquilamento de si mesmo é o único fito. Ou seja, existe desaparecimento do conflito, das relações de transferência, o mundo acaba e ficamos à mercê daquilo que nos suporta. O fundo de suporte deve necessariamente ser sensível, flexível, com ritmo. Tudo isto nos lembra o cotidiano que nos permeia e que 


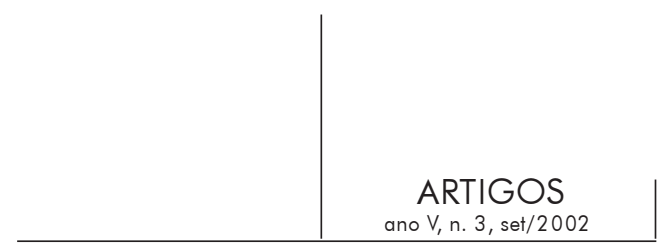

compartilhamos e que serve de fundo comum para a existência conflitiva e para um destino que não seja tal como se encontra na psicose melancólica.

\section{Referências}

Collomb, H. e Zwingelstein, J. Depressive states in an Afrikan community (Dakar). First Pan-African Conference, Abeokuta [Nigeria], 1962.

Hempel, Carl G. (1965). Fundamentals in Taxonomy. In: SAdler, John; Wiggins, Osborne; Schwartz, Michael (Orgs.). Philosophical perspectives on psychiatric diagnostic classification. Baltimore e Londres: The John Hopkins University Press,

Maldiney, Henry. L'existence dans la dépression et dans la mélancolie. In: Penser l’homme et la folie. Grenoble: Jérôme Millon, 1997.

Mauss, Marcel. Ensaio sobre a dádiva. Lisboa: Edições Setenta, 1950.

Ortigues, Edmond e Ortigues, Marie-Cecile (1973). Édipo africano. São Paulo: Escuta, 1989.

Ramos, Graciliano (1934). São Bernardo. 5. ed. Rio de Janeiro: José Olympio, 1953. Schotтe, Jacques. Comme dans la vie, en psychiatrie... Les pertubations de l'humeur comme troubles de base de l'existence. In Qu'est-ce que l'homme?, homenagem a Alphonse De Waelhens. Bruxelas: Facultés Universitaires Saint-Louis, 1982.

Tellenbach, Hubertus (1974). Melancolia. Tradução espanhola de A. Guera Miralles. Madrid: Editiones Morata, 1976.

\section{Resumos}

Este trabajo estudia la dimensión de la metáfora en la melancolía. Se busca diferenciar ésta de la depresión. Se muestra que las depresiones se presentan corrientemente con metáforas de caída y lucha. En las melancolías se agrega la dimensión del devenir como siendo alterada en la profundidad del propio cuerpo. Dos aspectos ligados al cuerpo son valorizados y transparentan la dificultad de devenir de las metáforas presentadas por el melancólico: la desvitalizacion y el bloqueo del ir y el venir. Los verbos subir y bajar y principalmente ir y venir, son indicados como importantes en las metáforas, justamente porque ellos expresan el bloqueo del sentir fundamental y por consiguiente de la dimensión del venir a Ser. Se presentan y se discuten ejemplos de São Bernardo, de Graciliano Ramos.

Palabras llave: Melancolía, depression, metáforas, Graciliano Ramos

Le travail étudie la dimension de la métaphore chez les mélancoliques. La mélancolie est différenciée de la dépression. Dans les dépressions est habituel les 


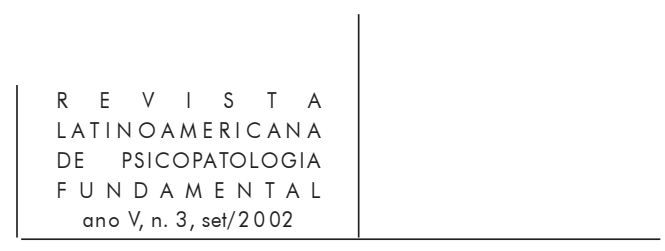

métaphores de lutte et de chute. Dans les mélancolies la dimension du devenir est vécue comme un changement dans la profondeur du corps propre. Deux aspects liés au corps sont évalués et devoilent la difficulté du devenir de l'Être du point de vue des métaphores présentées par le mélancolique: la desvitalization et le blocage radicaux qu'éprouvent l'Être des melancoliques. Les verbes monter et descendre et principalement aller et venir sont pointés comme important dans les métaphores parce qu'ils expriment le blocage du sentir fondamental et par conséquence de la dimension du devenir de l'Être. Exemples du roman São Bernardo, de Graciliano Ramos sont presentés et discutés.

Mots clés: Mélancolie, dépression, métaphores, Graciliano Ramos

In this article the author discusses the metaphorical dimension of melancholy, as differentiated from depression. Depressions are usually accompanied by metaphors about falls and struggles. In the melancholias, the dimension of becoming is also present, as one's being changed in the depth of one's own body. Two aspects related to the body are discussed, and reveal the difficulty of becoming from the point of view of metaphors presented by melancholic patients, that is, devitalization and the near impossibility of moving about. The verbs "going up" and "going down" and, especially, "coming" and "going" are indicated as important in metaphors because they express the basic blockage offeeling and, therefore, of becoming. Examples from Graciliano Ramos's novel São Bernardo are presented and discussed.

Key words: Melancholia, depression, metaphors, Graciliano Ramos

Versão inicial recebida em março de 2002

Aprovado para publicação em julho de 2002 